Article

\title{
Hybrid Nanocomposites of Cellulose/ Carbon-Nanotubes/Polyurethane with Rapidly Water Sensitive Shape Memory Effect and Strain Sensing Performance
}

\author{
Guanzheng Wu ${ }^{1,+}$, Yanjia Gu ${ }^{1,2,+}$, Xiuliang Hou ${ }^{1}$, Ruiqing Li ${ }^{1}$, Huizhen $\mathrm{Ke}^{3, * \mathbb{D}}$ and \\ Xueliang Xiao ${ }^{1, *}$ \\ 1 Key Laboratory of Eco-Textiles, Ministry of Education, Jiangnan University, Wuxi 214122, China; \\ 18084721450@163.com (G.W.); yanjiagu1984@163.com (Y.G.); kehuilzhen2013@163.com (X.H.); \\ LiRuiqing_1997@163.com (R.L.) \\ 2 Shenzhen Digital Life Institute, Shenzhen 581000, China \\ 3 Fujian Key Laboratory of Novel Functional Textile Fibers and Materials, Minjiang University, \\ Fuzhou 350108, China \\ * Correspondence: kehuizhen2013@163.com (H.K.); xiao_xueliang@163.com (X.X.); \\ + Equal authors.
}

Received: 26 August 2019; Accepted: 24 September 2019; Published: 27 September 2019

\begin{abstract}
In this work, a fast water-responsive shape memory hybrid polymer based on thermoplastic polyurethane (TPU) was prepared by crosslinking with hydroxyethyl cotton cellulose nanofibers (CNF-C) and multi-walled carbon nanotubes (CNTs). The effect of CNTs content on the electrical conductivity of TPU/CNF-C/CNTs nanocomposite was investigated for the feasibility of being a strain sensor. In order to know its durability, the mechanical and water-responsive shape memory effects were studied comprehensively. The results indicated good mechanical properties and sensing performance for the TPU matrix fully crosslinked with CNF-C and CNTs. The water-induced shape fixity ratio $\left(R_{f}\right)$ and shape recovery ratio $\left(R_{r}\right)$ were $49.65 \%$ and $76.64 \%$, respectively, indicating that the deformed composite was able to recover its original shape under a stimulus. The TPU/CNF-C/CNTs samples under their fixed and recovered shapes were tested to investigate their sensing properties, such as periodicity, frequency, and repeatability of the sensor spline under different loadings. Results indicated that the hybrid composite can sense large strains accurately for more than $10^{3}$ times and water-induced shape recovery can to some extent maintain the sensing accuracy after material fatigue. With such good properties, we envisage that this kind of composite may play a significant role in developing new generations of water-responsive sensors or actuators.
\end{abstract}

Keywords: hybrid nanocomposites; rapid recovery; sharp memory polymer; strain sensor

\section{Introduction}

In the past decades, shape memory polymers (SMPs) have gained attention because of their responsive manners to various types of stimuli (including water, electrical, heat, and $\mathrm{pH}$ ) [1]. Visually, SMPs can recover their original shapes from temporarily deformed shapes when exposed to appropriate environmental stimuli [2-4], namely, the shape memory effect (SME), which is due to their unique molecular structures. According to a proposed structural model of SMP, a polymer with SME should be composed of molecular switches and netpoints [3-5]. When exposed to some predetermined external stimuli, the molecular switches play an important role in dominating the shape fixity and recovery, which may be crystalline phase or amorphous polymer chains. Networks may consist of 
either chemical or physical crosslinking points that determine the permanent shape [6]. Regarding triggers, like electric, $\mathrm{pH}$, light, organic solvents, and even water [7], SMPs can be classified into many types, like temperature-actuated SMPs, electric-actuated SMPs, $\mathrm{pH}$-actuated SMPs, light-actuated SMPs, solvent-actuated SMPs, and water-actuated SMPs [8,9]. In recent years, SMPs have been considered as one of the most promising smart materials, receiving extensive interest from scientific researchers $[10,11]$.

The advantages of SMPs have resulted in great potential applications in many areas. For instance, smart fabrics, strain sensors, biomedical materials, and aerospace applications [12-14]. Nevertheless, some obstructions still exist that prevent SMPs' widespread application. Customarily, in comparison with shape memory alloys (SMAs), SMPs have relatively low recovery stress [15]. This is a limiting factor in many applications, particularly where SMPs must conquer a large resisting stress during shape recovery [16]. Therefore, in order to enhance the mechanical properties and to obtain multiple functionalities, many kinds of nano-fillers have been used to modify polyurethane $[17,18]$.

Zhu et al. [19] reported a water-actuated SMP with an unprecedentedly rapid switchable SME that was fabricated by adding a crystalline nano-whiskers percolation network to TPU. Li et al. [20] developed pH-actuated SMP nanocomposites by blending poly(ethylene glycol, PEG)-poly( $\varepsilon$-caprolactone, PCL)-based polyurethane with cellulose nanocrystals (CNCs), which were functionalized with pyridine moieties $\left(\mathrm{CNCs}-\mathrm{C}_{6} \mathrm{H}_{4} \mathrm{NO}_{2}\right)$ through hydroxyl substitution of $\mathrm{CNCs}$ with pyridine-4-carbonyl chloride and carboxyl groups $\left(\mathrm{CNCs}-\mathrm{CO}_{2} \mathrm{H}\right)$ via 2,2,6,6-tetramethyl-1-piperidinyloxy (TEMPO)-mediated surface oxidation. Liu et al. [21] introduced CNC into the mixture of PEG and PCL. The mechanical properties of the mixture were significantly improved, and a nanocomposite SMP that was simultaneously thermal- and water-responsive was thereafter prepared. Through these previous studies, we found that $\mathrm{CNCs}$ have a good reinforcing effect on the mechanical properties of the matrix of SMP. Moreover, due to the high strength, Young's modulus, and conductivity of carbon nanotubes [22,23], such nanomaterials can enhance the matrix functions of SMPs. Yu et al. [24] reported that a small proportion of CNTs can improve the thermal properties of SMP nanocomposites. Du et al. [25] developed an electroactive SMP that was prepared by PVA and CNTs. It was reported that the reinforcement of multi-walled CNTs can lead to enhanced electrical and thermal characteristics of the PVA matrix. Chen et al. [26] developed CNTs array-based epoxy-SMP (ESMP) nanocomposites. In this material, the CNTs were interconnected with each other and a three-dimensional (3D) network was formed. As a result, both the thermal and electrical conductivities of the high array of CNTs/ESMP nanocomposites were higher than the random CNTs/ESMP composite fabricated by conventional high-speed mechanical stirring [27].

Further, sensors, as one of the most useful applications of SMPs, plays an important role in human motion monitoring. A series of important achievements have been made in the field of flexible wearability for scientific researchers [28-30]. For example, Zhou et al. [31] developed a strain sensor with high sensitivity, high tensile property, and high linearity, which was fabricated by wet spinning of CNT-doped thermoplastic elastomer. Therefore, the mechanical properties of SMPs may be highly enhanced by CNCs, and the electrical conductivity and thermal conductivity of SMPs may be given by CNTs [32]. In this work, a multi-responsive SMP composite based on TPU was fabricated by crosslinking with CNCs and CNTs, hopefully in combination with the advantages of CNCs, CNTs, and TPU for fine mechanical properties, stimuli-responsive, and electrical conductivity, in order to obtain an ideal sensing performance.

\section{Materials and Methods}

\subsection{Raw Materials}

Thermoplastic polyurethane granules (TPU, type of BT-70ARYU, hardness of $70 \pm 2$ Shore A, density of $1.13 \mathrm{~g} / \mathrm{cm}^{3}$ ) were purchased from Shanghai Yongyi Industrial Co., Ltd. (Shanghai, China). $\mathrm{Mn} \approx 0.2 \times 10^{5}$. Cotton cellulose nanofiber (CNF-C, with a large amount of CNCs, solid content is 
$1.0 \mathrm{wt} \%$, particle size is around $6.5 \mathrm{~nm}$, length is around $1000 \mathrm{~nm}$ ) was purchased from Guilin Qihong Technology Co., Ltd. Carbon nanotubes size (CNTs, content is $5.0 \pm 0.2 \%$, diameter is in the range of 30 and $60 \mathrm{~nm}$, length is 10 to $30 \mu \mathrm{m}$ ) were purchased from Shenzhen Tuling Evolution Technology Co., Ltd. (Shenzhen, China) N, N-dimethylformamide (DMF, CP, $\geq 99.0 \%$ ) was purchased from Sinopharm Chemical Reagent Co., Ltd. The linear type of TPU was applied without further purification, but CNF-C and CNTs were freeze-dried for $72 \mathrm{~h}$, and CNTs were ground into powder. Then the raw materials were kept in a dry atmosphere for further use.

\subsection{Preparation of TPU/CNF-C/CNTs Hybrid Films}

TPU/CNF-C/CNTs hybrid films were prepared through solution blending [33]. Originally, the TPU/CNF-C solution and CNTs solution were prepared separately. Afterwards, the two kinds of solutions were mixed together. Taking the TPU/CNF-C/CNTs (100:5:5 wt\%) (named TPU/CNF-C/CNT-5) as an example, the specific steps were as follows: Firstly, TPU $(4.5 \mathrm{~g})$ and CNF-C $(0.225 \mathrm{~g})$ were dissolved in $25 \mathrm{~mL}$ of DMF solvent at $75^{\circ} \mathrm{C}$ for $1 \mathrm{~h}$ with the aid of magnetic stirring. CNTs $(0.225 \mathrm{~g})$ nanoparticles were dispersed in $20 \mathrm{~mL}$ of DMF solvent for about $0.5 \mathrm{~h}$ under ultrasonic conditions. Afterwards, the CNTs solution was gradually poured into the TPU/CNF-C solution, then the mixture was further stirred for $2 \mathrm{~h}$. Ultimately, the TPU/CNF-C/CNTs mixed solution was poured into a petri dish and preserved in an oven at $75^{\circ} \mathrm{C}$ for enough time to eliminate the solvent inside, then a TPU/CNF-C/CNTs film was obtained. In order to investigate the effect of CNTs on the properties of the TPU/CNF-C/CNTs system, a series of nanocomposite thin films were prepared with different contents of CNTs, as shown in Table 1. Here, "CNT-X" followed by a number means the approximate weight percentage of CNTs in the fabricated system.

Table 1. Composition of the control sample and as-fabricated TPU/CNF-C/CNTs nanocomposites.

\begin{tabular}{ccccc}
\hline Sample Code & TPU/g & CNF-C/g & CNTs/g & CNTs/wt \% \\
\hline TPU/CNF-C/CNT-5 & 4.5 & 0.225 & 0.225 & 5.0 \\
TPU/CNF-C/CNT-6 & 4.5 & 0.225 & 0.27 & 6.0 \\
TPU/CNF-C/CNT-7 & 4.5 & 0.225 & 0.315 & 7.0 \\
TPU/CNF-C/CNT-8 & 4.5 & 0.225 & 0.36 & 8.0 \\
\hline
\end{tabular}

For the sake of measuring properties of as-made films, all samples were processed into the same thickness of $0.15 \mathrm{~mm}$ under the melt temperature of $130^{\circ} \mathrm{C}$ and the compression pressure of $15 \mathrm{MPa}$ (R-3212 type of hot press, Wuhan Qien Sci-Tech Co., Ltd., China). Then, the TPU/CNF-C/CNTs thin films with the same thickness were obtained using the hot-press process [34].

\subsection{Characterization by Attenuated Total Reflectance Fourier Transform Infrared Spectroscopy (ATR FT-IR)}

Fourier transform infrared spectroscopy spectra of the as-made samples were analyzed using a Nicolet is 10 spectrometer (Thermo Fisher SCIENTIFIC-CN, Waltham, USA) in the ATR module at room temperature from 4000 to $560 \mathrm{~cm}^{-1}$ at a resolution of $4 \mathrm{~cm}^{-1}$.

\subsection{Characterization by Wide Angle X-Ray Diffraction (WAXRD)}

Wide angle X-ray diffraction (WAXRD) is an X-ray diffraction technique that can be used to determine the crystalline structure of polymers [35]. The crystalline structure of samples was investigated using a D2 PHASER X-ray powder diffractometer (Brook AXS Ltd., Karlsruhe, Germany). The X-ray source was the ceramic type, $\mathrm{Cu}$ target, and the power of the optical tube was $2.2 \mathrm{~kW}$. The range of the scanning angle was 5 to $90^{\circ}$, resolution ratio was 0.026 , and the scanning rate was $2^{\circ} / \mathrm{min}$. 


\subsection{Characterization by Differential Scanning Calorimetry (DSC)}

The thermal properties of samples were investigated using a differential scanning calorimeter (DSC) Q200 (TA Instruments-Waters LLC, Hangzhou, China), which can be used to characterize the glass transition temperature [36]. A sample of about $5 \mathrm{mg}$, which was cut from the compression-molded sheet, was directly heated from 40 to $120^{\circ} \mathrm{C}$ at a heating rate of $10{ }^{\circ} \mathrm{C} / \mathrm{min}$. All the measurements were conducted in a nitrogen $\left(\mathrm{N}_{2}\right)$ atmosphere.

\subsection{Characterization by Tensile Tests}

The tensile tests were carried out at room temperature $\left(25^{\circ} \mathrm{C}\right)$ using a CMT4101 Electronic Universal Testing Machine (Shenzhen New Sansi Material Testing Co., Ltd., Shenzhen, China) at a constant crosshead rate $(30 \mathrm{~mm} / \mathrm{min})$. The rectangular film sample for the tensile tests was cut from the hot-pressed sheet with a width of $10 \mathrm{~mm}$ and a length of $60 \mathrm{~mm}$. The original distance between two clamps was set at $50 \mathrm{~mm}$ [37]. All samples were stretched until breakage for a single tensile test.

\subsection{Shape Memory Behavior Measurements}

Different from the single tensile test, to study the strength and strain at break, a cyclic tensile program was carried out to investigate the shape memory effect of the as-made samples, as shown in Figure 1a. Here, the sample was firstly immersed in deionized water (set at $25^{\circ} \mathrm{C}$ ) for $1 \mathrm{~h}$ (Figure $1 \mathrm{a}-\mathrm{b}$ ). Then, the sample was taken out quickly and stretched at a constant cross-head rate $(30 \mathrm{~mm} / \mathrm{min})$ to a strain $\left(\varepsilon_{m}\right)$ of $40 \%$ at an ambient temperature of $22{ }^{\circ} \mathrm{C}$ (Figure 1a-c). Then, the stretched strain was maintained for $10 \mathrm{~min}$ (Figure 1a-d), and the sample was dried by an air blower during the strain. A fixed strain $\left(\varepsilon_{u}\right)$ was recorded accordingly. Subsequently, the stretched film was released to the original clamped distance with the temporarily fixed strain (Figure 1a-e), and the sample was immersed in water again for $10 \mathrm{~min}$ of shape recovery (Figure 1a-f). The second tensile started from the recovered shape (a residual/unrecovered strain $\varepsilon_{p}$ ) of the sample. The operations were repeated three times to form a water-responsive cyclic tensile test for SME quantification. The cyclic tensile test followed Zhu et al.'s work [19].

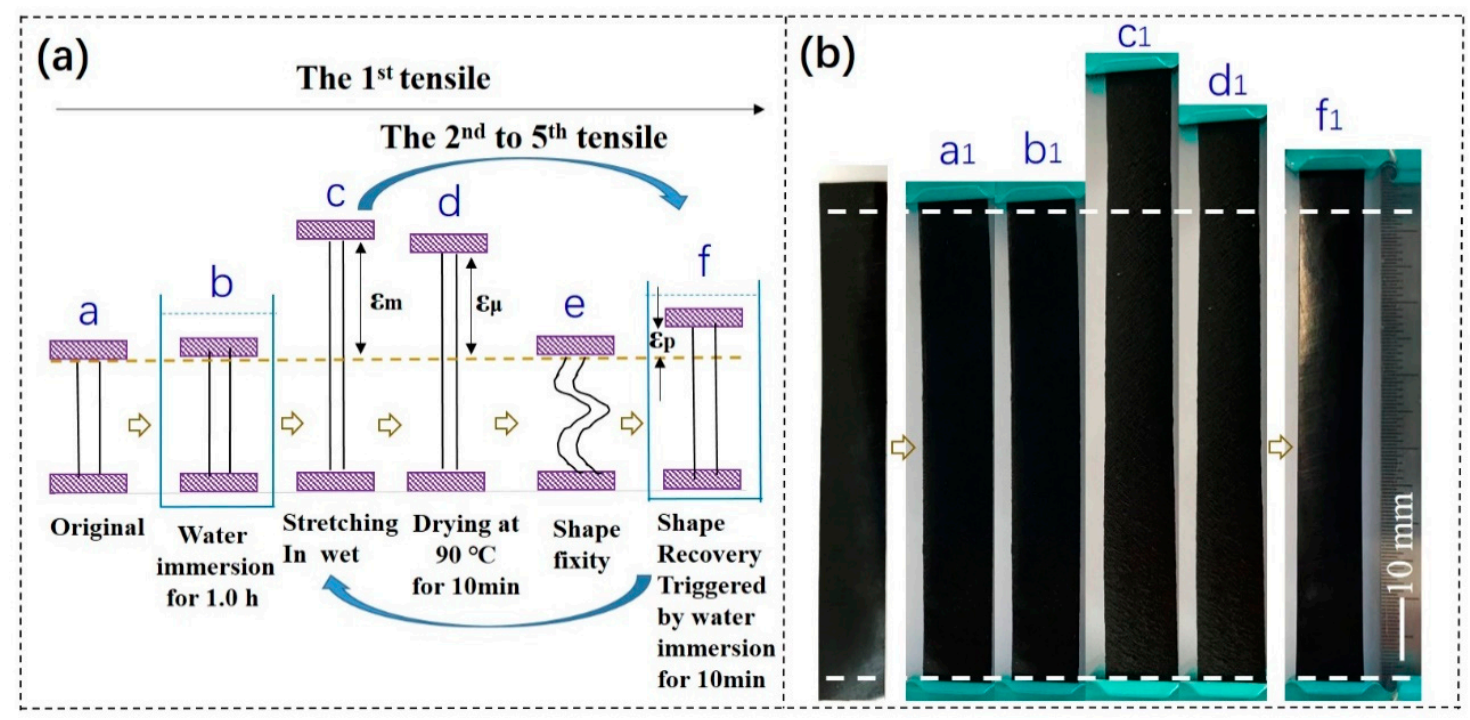

Figure 1. The cyclic tensile test to demonstrate the program of water-stimulus SME.

In Figure $1 \mathrm{a}, \mathrm{N}$ is the cycling number, $\varepsilon_{m}$ is the set strain for shape fixation, $\varepsilon_{u-N}$ means the real fixed strain at the step of Figure $1 \mathrm{a}-\mathrm{d}$, and $\varepsilon_{p-N}$ means the unrecovered strain after the shape recovery. The shape fixity ratio $\left(R_{f}\right)$ and shape recovery ratio $\left(R_{r}\right)$ were calculated according to Equations (1) and (2) [38,39]: 


$$
\begin{gathered}
R_{f}=\frac{\varepsilon_{u-N}}{\varepsilon_{m}} \times 100 \% \\
R_{r}=\frac{\varepsilon_{m}-\varepsilon_{p-N}}{\varepsilon_{m}-\varepsilon_{p-(N-1)}} \times 100 \%
\end{gathered}
$$

Figure $1 b$ is the real sample in the SME test diagram corresponding to the schematic of Figure $1 \mathrm{a}$. From Figure $1 b\left(a_{1}\right.$ to $\left.f_{1}\right)$, the illustration shows the process of shape fixity and shape recovery in SME.

\subsection{Tests of Sensing Performance}

The sensing performance tests were also carried out at room temperature $\left(20{ }^{\circ} \mathrm{C}\right)$ using the CMT4101 Electronic Universal Testing Machine (Shenzhen New Sansi Material Testing Co., Ltd., Shenzhen, China) [37]. The rectangular film sample for the tensile tests was cut from the hot-pressed sheet with a width of $10 \mathrm{~mm}$ and a length of $50 \mathrm{~mm}$. The distance between two clamps was maintained at $40 \mathrm{~mm}$, then the resistance of the sample was tested by a multimeter during the stretching. The two ends of the sample were fixed on the fixture of the multimeter. The resistance of the corresponding point was recorded at a frequency of $1 \mathrm{~Hz}$, and the stretched strain was set as $40 \%$.

\section{Results and Discussions}

\subsection{Physical Properties of TPU/CNF-C/CNTs Films}

The chemical structures and physical properties of the as-made water-responsive polyurethane nanocomposites were characterized by FT-IR, XRD, and DSC, respectively, as shown in their spectra in Figure 2.
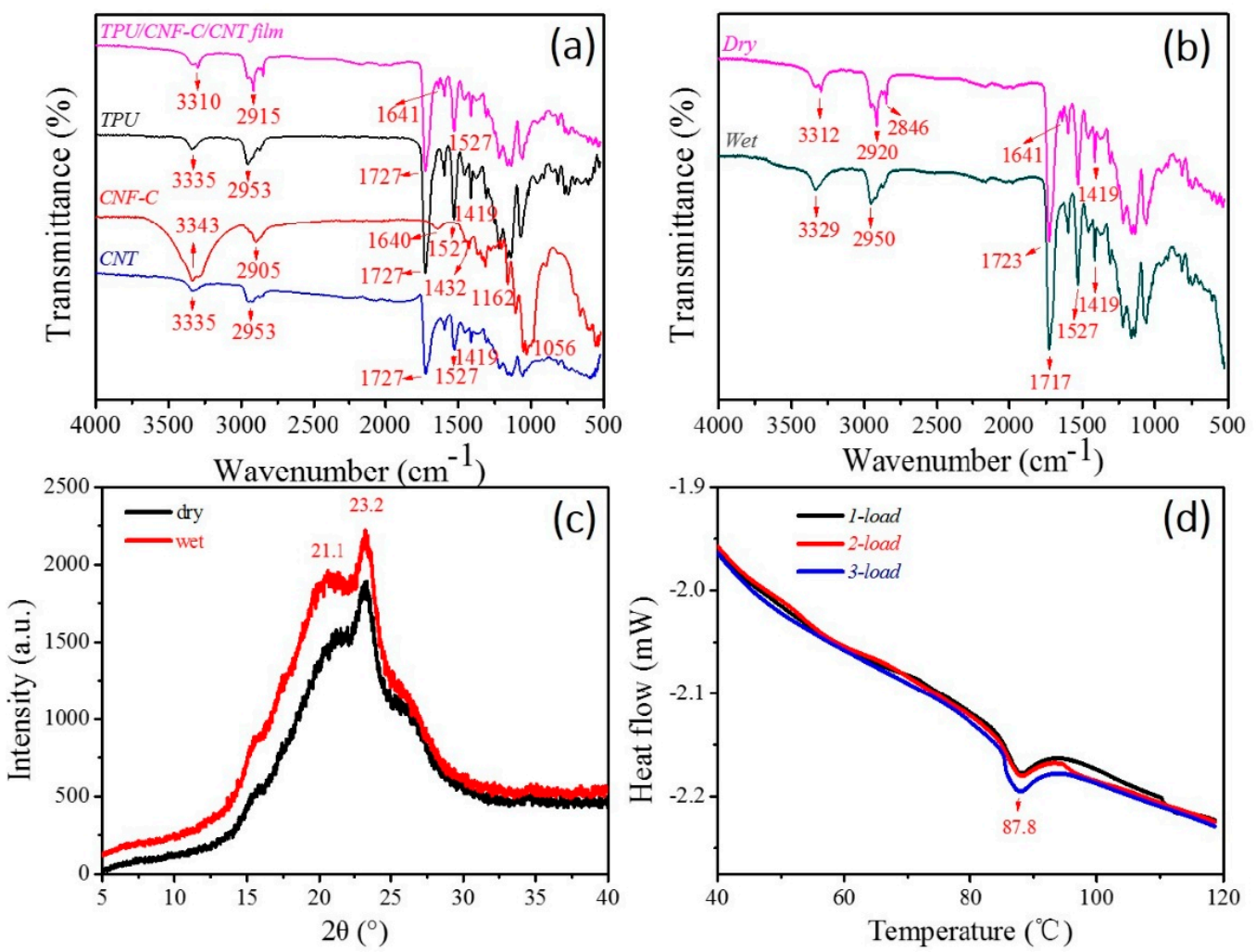

Figure 2. Chemical structure and physical properties of as-made water-responsive polyurethane composition, (a) FT-IR results of TPU/CNF-C/CNTs film, TPU, CNF-C, CNTs; (b) FT-IR results of TPU/CNF-C/CNTs films under original (dry) and water (wet); (c) XRD patterns of TPU/CNF-C/CNTs film under dry and wet states; (d) DSC characterization of TPU/CNF-C/CNTs film from 40 to $120^{\circ} \mathrm{C}$ for three loads. 
Among them, FT-IR was adopted to characterize the chemical interaction of molecules of TPU, CNF-C, and CNTs, and the change of TPU/CNF-C/CNTs from dry to wet states. Specifically, in Figure 2a, the characteristic peaks of $-\mathrm{NH}$ at 3335 and $2953 \mathrm{~cm}^{-1}$ were slightly interrupted by the similar polar group of $-\mathrm{OH}$ from $\mathrm{CNF}-\mathrm{C}$ and CNTs. The unique characteristic peak, representing the hydrogen bonding interaction of $-\mathrm{COOH}$ and $-\mathrm{OH}$, at $1640 \mathrm{~cm}^{-1}$ from $\mathrm{CNF}-\mathrm{C}$ was also brought into the composite system by the observed peak at $1641 \mathrm{~cm}^{-1}$. The other characteristic peaks were the main peak features from TPU. As shown in Figure 2b, the penetration of aqueous molecules into the composite system breaks up the hydrogen bonding of $-\mathrm{COOH}$ and $-\mathrm{OH}$, giving rise to the disappearance of the characteristic peak at $1641 \mathrm{~cm}^{-1}$ for the wet samples [40]. Because of hydrophobic nature of the TPU matrix and the ATR FT-IR characteristic method $(10 \mu \mathrm{m}$ of IR depth into the sample surface), the wet sample of the nanocomposite displays a slightly broad peak at $3400 \mathrm{~cm}^{-1}$ close to 3329 $\mathrm{cm}^{-1}$ due to water volatilization. In turn, a drying process eliminates the aqueous molecules, with a disappearance of the characteristic peak of the -OH group $\left(3400 \mathrm{~cm}^{-1}\right)$, re-forming the hydrogen bonds and showing a characteristic peak at $1641 \mathrm{~cm}^{-1}$. This reversible behavior related to the conversion between dry and wet conditions suggests that the intermolecular hydrogen bonds undergo reversible destruction and formation processes accordingly. Combining the results of the FT-IR tests, a scheme of the interfacial interactions mechanism based on hydrogen bonding is exhibited in Figure 3.

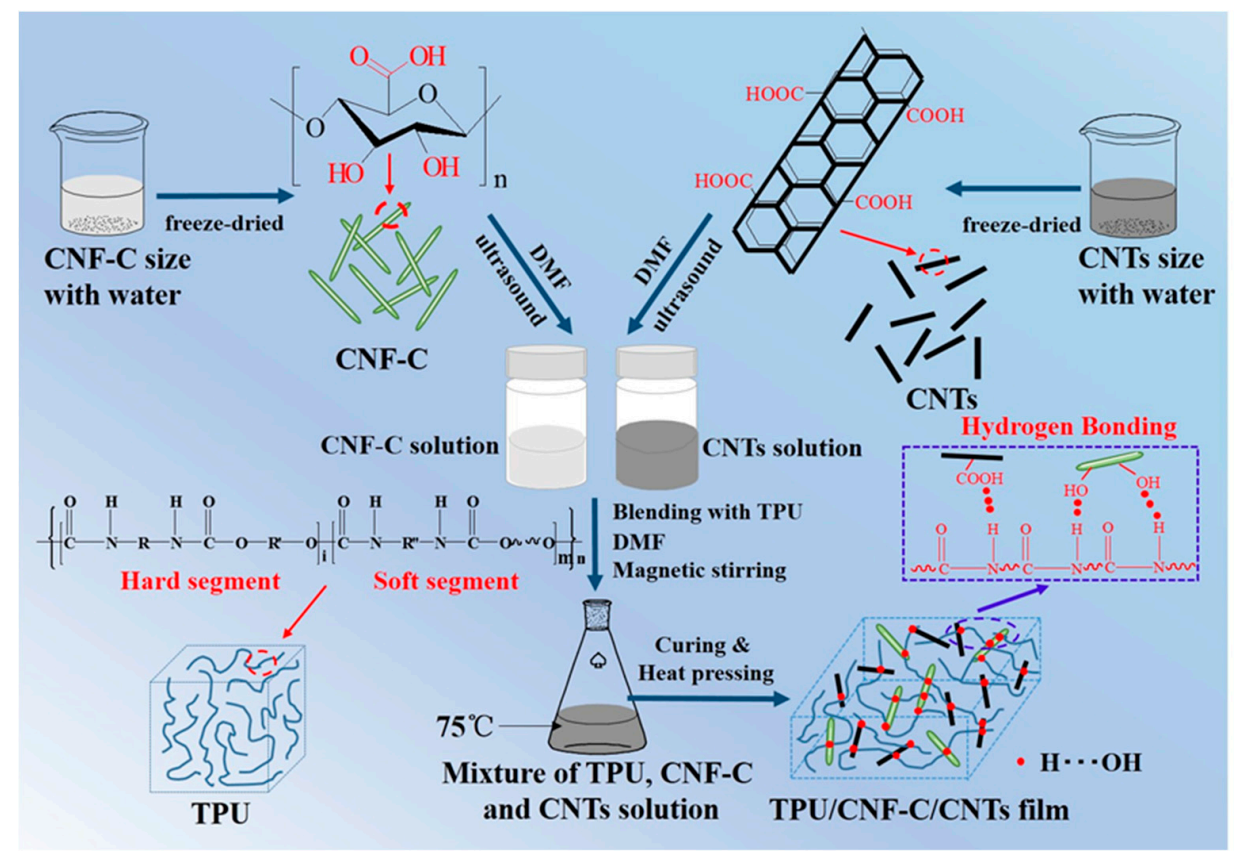

Figure 3. Schematic illustration of the hydrogen bonding interaction mechanism among molecules of TPU, CNF-C, and CNTs, and the film formation of TPU/CNF-C/CNTs.

The nanoparticles of CNF-C and CNTs were derived from the CNF-C and CNTs size with water via a freeze-dried process. Dissolved TPU solution was blended evenly with CNF-C and CNTs nanaoparticles, then TPU/CNF-C/CNTs nanocomposite films were obtained after a curing process $\left(75^{\circ} \mathrm{C}\right)$. Furthermore, a large amount of $-\mathrm{OH}$ and the rigid structure of the $\mathrm{CNF}-\mathrm{C}$ contributed to dual functions of physical and chemical crosslinking points in the nanocomposite film. A great quantity of the $-\mathrm{COOH}$ group was distributed on the surface of rod-like CNTs, which could perform a similar function as CNF-C. In addition, CNF-C and CNTs can be combined via hydrogen bonding. After blending, CNF-C and CNTs can disperse well in the TPU matrix. The existence of the hydrogen bonding among the TPU matrix, CNF-C, and CNTs can form a three-dimensional network structure [34].

The XRD patterns of TPU/CNF-C/CNTs hybrid films were obtained under two states as shown in Figure 2c. The diffraction shoulders and peaks at the dry state were due to the wetting and hydration 
with similar shape peaks, especially at the abscissa of $2 \theta=21.1^{\circ}$ and $23.2^{\circ}$, indicating the strong characteristic $\beta$-keratin crystalline phases. The intensities of both characteristic peaks at the wet state were greater than those of the dry state. This indicates the invariable amount of the crystalline phase during water-stimuli SME. The existing XRD peaks of TPU/CNF-C/CNTs under dry and wet conditions indicate that the crystalline phase may take a net point role in the water-sensitive SME of the hybrid system.

The DSC patterns of TPU/CNF-C/CNTs hybrid film were obtained from 40 to $120^{\circ} \mathrm{C}$ under three heating loads, as shown in Figure 2d. The DSC curves coincide with each other basically. Each curve manifests that the enthalpy decreases during the heating process of the film, and reverses its initial value during the cooling process, which is in relation to the films in the progress of shape recovery. The endothermic peak indicates that the glass transition temperature $(\mathrm{Tg})$ of as-made film sample is $87.8^{\circ} \mathrm{C}$. The measured $\mathrm{Tg}$ provides a theoretical basis for setting the shape fixation temperature, which should be a value higher than $\mathrm{Tg}$. In this work, a temperature of $90^{\circ} \mathrm{C}$ was used to set the temporary shape fixation of sample.

\subsection{Mechanical Properties of TPU/CNF-C/CNTs Films}

The measured tensile stress-strain curves are shown in Figure 4a for as-made TPU/CNF-C/CNTs-5, TPU/CNF-C/CNTs-6, TPU/CNF-C/CNTs-7, and TPU/CNF-C/CNTs-8. Each film sample presents a smoothly nonlinear elastic behavior until the breaking point, which is mainly ascribed to the fracture of the film along the stretching direction. Some studies, including the new reports [41-44], suggest that the commixture with CNF-C and CNTs can enhance the mechanical properties of TPU significantly, especially the tensile strength and elongation at break (Figure $4 \mathrm{~b}$ ), but with the continued increase of the content of nanoparticles, the strength of TPU/CNF-C/CNTs nanocomposite films would decrease slowly. Figure $4 \mathrm{~b}$ shows the best mechanical properties of the TPU/CNF-C/CNTs- 6 film. It can achieve $31.78 \mathrm{MPa}$, and the corresponding strain at break is $904.1 \%$. In view of the above mechanical performance, the sample of TPU/CNF-C/CNTs- 6 was selected for the tests of typical SME and sensing performance [44].

(a)

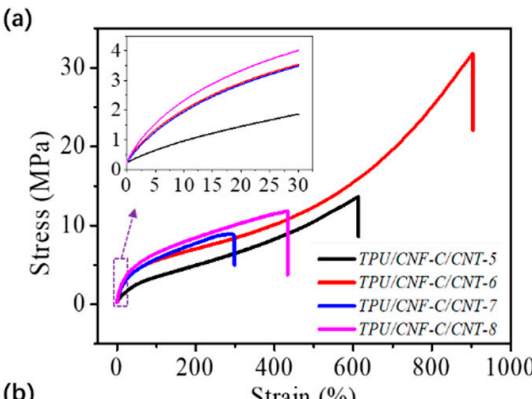

(b)

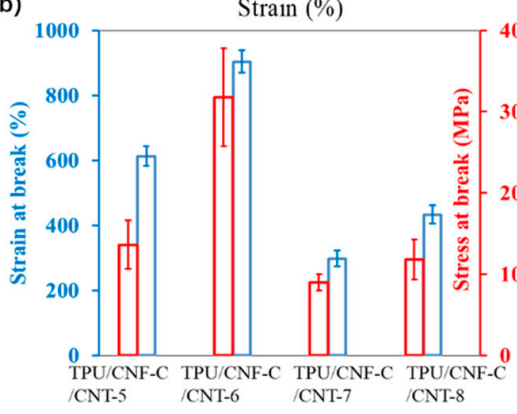

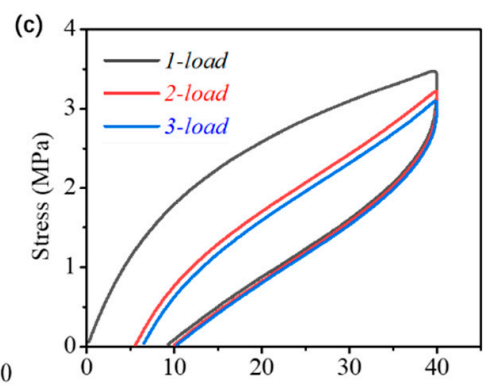
(d)

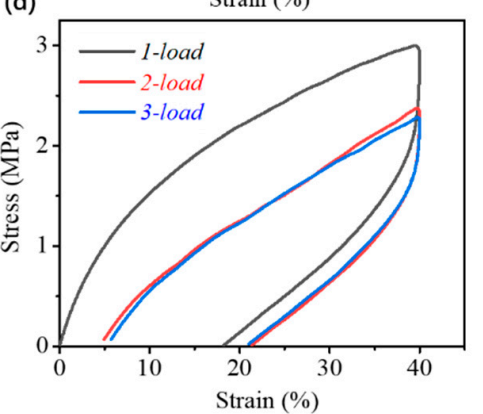

Figure 4. Measured mechanical properties of nanocomposite films, (a) typical tensile stress-strain curves, the inset shows the stress-strain curve of each sample stretching up to $30 \%$; (b) the strain and stress values at break for TPU/CNF-C/CNTs-5, TPU/CNF-C/CNTs-6, TPU/CNF-C/CNTs-7, TPU/CNF-C/CNTs-8; (c) experimental cyclic tensile of TPU/CNF-C/ CNTs-6 film without using any stimulus; (d) cyclic tensile of TPU/CNF-C/CNTs-6 film under water stimulus. 
For the measured cyclic tensile curves of Figure 4c,d, Equations (1) and (2) can be used to quantitatively analyze the SME of film sample responsive to water. Figure $4 \mathrm{c}$ indicates a fixed strain $R_{f}$ of measured $25.27 \% \varepsilon_{u-N}=10.1 \%, \varepsilon_{m}=40 \%$ ) while Figure $4 \mathrm{~d}$ presents the fixed strain, $R_{f}$, measured as $49.65 \% \varepsilon_{u-N}=19.50 \%, \varepsilon_{m}=40 \%$ ). This indicates that water is an effective stimulus to fix the temporary shape of the as-made nanocomposite film.

In Figure 4a, the inset image shows a slightly nonlinear increase relationship of stress and strain until $30 \%$, and reflects a unique tensile deformation of the macromolecular sample before yield point. Plastic deformation of the film was increased after the yield point, which gives the possibility of shape fixation and recovery for a specific stimulus. Here, for $R_{r}$, water as a kind of stimulus leads to a larger degree of shape recovery (76.64\%) than the film without stimulus (45.54\%). In this case, water initiates a higher recovery by the stress released from net points via the switch units (like hydrogen bonds), which are unlocked through aqueous molecules. To illustrate the point, all the tests were conducted under the same tensile speed in $30 \mathrm{~mm} / \mathrm{min}$, and remained at the extreme point for $10 \mathrm{~min}$ [45]. Contrasting findings showed that water can improve the $R_{f}$ and $R_{r}$ values of as-made composite samples effectively. The values depend on the interaction of the stimulus, net points, and switches [45]. In such a water-sensitive SMP, CNF-C and CNTs were considered as net points, and the mechanical properties of the nanocomposite SMP were significantly enhanced. Through FT-IR characterization, the intermolecular hydrogen bonding was regarded as the corresponding switch. The combination of a percolation network CNF-C, CNTs, and TPU matrix is the microstructural precondition for rapid switchable water-sensitive SME in TPU/CNF-C/CNTs films. Original TPU/CNF-C/CNTs film can be softened via water molecules, with the breakage of hydrogen bonds among the TPU and nanoparticles. The manually deformed shape was relatively easy to be fixed because a drying process can lead to shape fixation through the formation of a three-dimensional network, with individual nanoparticles crosslinking by hydrogen bonds after the removal of the water molecules. In the procedure of shape recovery, water as an external stimulus leads to an opening of switches among the TPU and nanoparticles, and a shape recovery would be noted by the water triggering the system [19].

\subsection{Rapid Response to Water Stimulation}

Figure 5 shows the process of TPU/CNFC/CNTs film under a continuity of water stimuli to investigate its SME. First, a dry straight film was folded in half, and then was immersed in water $\left(20^{\circ} \mathrm{C}\right)$ for one hour. The folded film was then taken out of the water under constrained conditions and heated in an oven to fix the folded shape at $90{ }^{\circ} \mathrm{C}$. The dried folded shape was then fixed, as mentioned above, and the as-made film with structural water and hydrogen bonds was fixed with the shape. The folded film was then put into water $\left(20^{\circ} \mathrm{C}\right)$, and a response of the film was noted by recording the shape recovery behavior, as shown by the few screenshots of the whole recovery process in Figure 5.

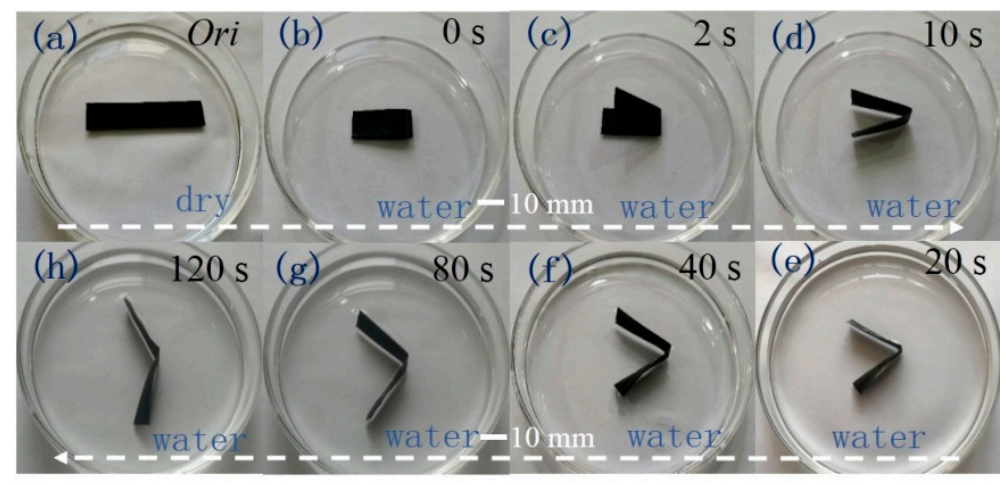

Figure 5. Shape recovery of manually deformed TPU/CNF-C/CNTs film in water.

With an increased time of the temporarily fixed shape of film in water, the folded angle of the sample increased gradually. As shown in Figure $5 b-h$, a turning over behavior of the film in water is 
noted at step $\mathrm{b}-\mathrm{d}$, indicating enough stress was released from the switch opening by water even to the extent that it was higher than the film's weight. Under deep impregnation of water into the film, the final recovered shape is close to its original shape at $120 \mathrm{~s}$, indicating a relatively fast response of the as-made film with manually deformed shape exposure to water. Then, for such a hybrid nanocomposite, aqueous molecules play an important role in water-sensitive SME, and hydrogen bonds ought to be the switch unit in the system [46]. The shape-fixed film quickly recovers its original state because of the quick action of aqueous molecules and switch units.

\subsection{Characterization of Sensing Performance}

With the involvement of CNTs in composites, electrical conductivity was applied to the film. Elasticity and electrical conductivity endow the developed nanocomposite with a sensing function. However, for most strain sensors in composite systems, strain relaxation is an inevitable factor, leading to sensing failure for thousands of usages, thus SME may be an effective way to enhance the sensing durability. Under this consideration, the factors affecting a sensor performance were investigated with the involvement of water-sensitive SME. Here, in Figure 6a, electrical conductivity was tested by an electrochemical workstation. The measured resistance for an original-shaped sample was $46.986 \mathrm{k} \Omega$ (the length, width, and thickness of the sample were 100,10, and $0.15 \mathrm{~mm}$ ) with a calculated electrical conductivity of $0.142 \mathrm{~S} / \mathrm{m}$.
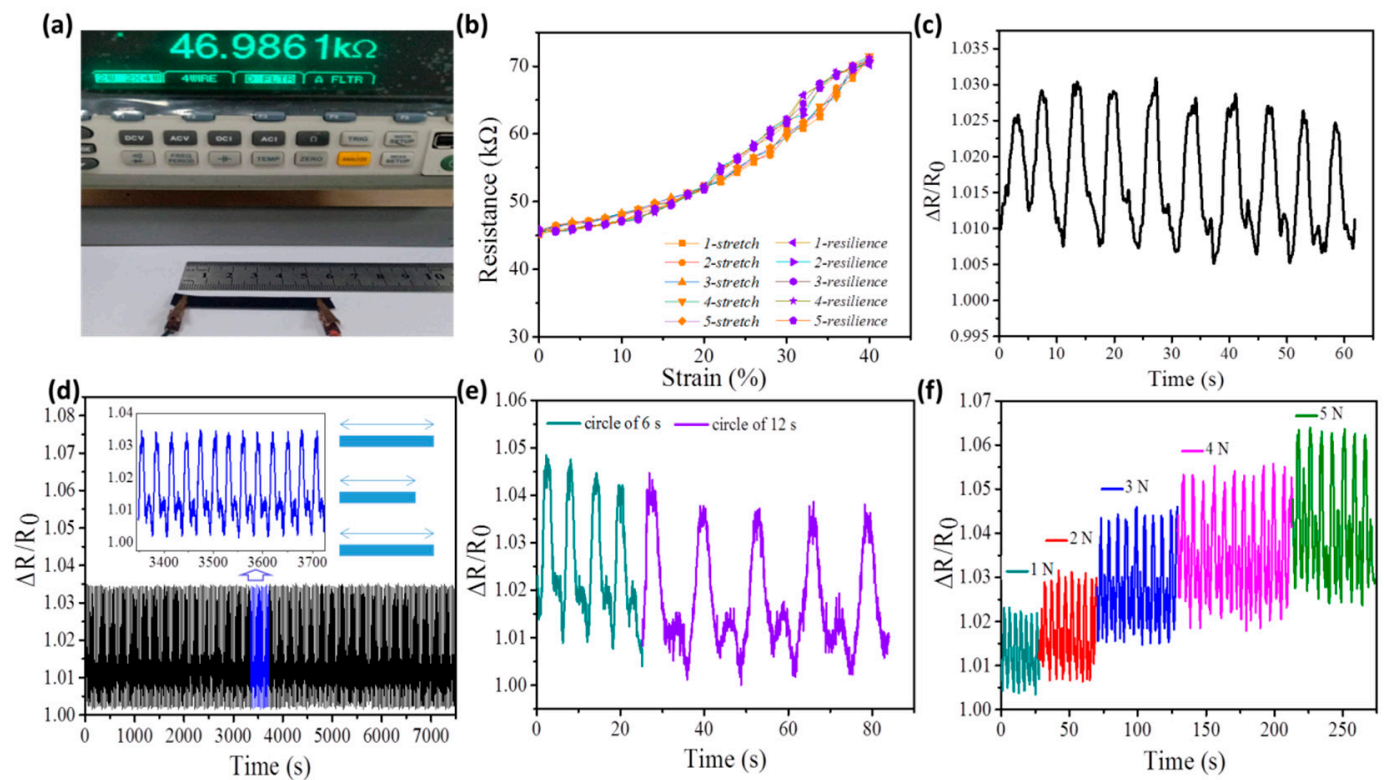

Figure 6. Characteristics of as-made TPU/CNF-C/CNTs nanocomposite as strain sensor, (a) electrical conductivity of TPU/CNF-C/CNTs film; (b) cycling test showing relative resistance change with tensile strain in the range of $0 \%$ to $40 \%$; (c) periodicity test curves of the film sample under a constant stress of 1.33 MPa; (d) repeatability test curves under a constant stress of $2.0 \mathrm{MPa}$ for the change of $\Delta \mathrm{R} / \mathrm{R}_{0}$ values after 1000 cycles of repeatable stretch, inset: enlarged image of 3348 to $3742 \mathrm{~s}$; (e) relative resistance change of strain sensors during the cyclic stretching with two different stretching rates (30\%, $60 \%)$; (f) repeatability test curves under constant stresses of $0.67,1.33,2.0,2.67$, and $3.33 \mathrm{MPa}$ for the change of $\Delta \mathrm{R} / \mathrm{R}_{0}$ values.

The strain-sensitivity relationship was measured by an ALJ-50HB manual screw tension tester, which has an electrochemical workstation to record the resistance (Figure $6 \mathrm{~b}$ ). It expounds the change of the relative resistance $\left(\Delta R / R_{0}\right)$ of the sensor related to the tensile strain $(\varepsilon)$ of the film, which is defined as the ratio of resistance change $(\Delta R)$ to the original resistance $\left(R_{0}\right)$ before stretching [47]. Here, a monotonic increase of $\Delta R / R_{0}$ can be seen with the strain between $0 \%$ and $40 \%$ (five times reversion). The increase of tensile strain leads to a gradual increase of non-communicating CNTs particles in the 
film, leading to an increase of the resistance. Gauge factor $\left(\mathrm{GF}\right.$, defined as $\left(\Delta \mathrm{R} / \mathrm{R}_{0}\right) / \varepsilon$ ) was reflected by the slope of the relative resistance change versus the applied strain. These resistive-type strain sensors rely on numerous features, such as the content of conductive components in the sensor. Then, the curve can be divided into two phases, $0 \%$ to $20 \%$ and $20 \%$ to $40 \%$ string with a GF of 0.79 and 1.93 , respectively, which will be discussed in Figure 7 in detail.

Besides the sensitivity study, the periodicity, signal stability, and repeatability are all parameters in consideration of the new composite film for the suitability of a strain sensor [48]. Here, Figure $6 \mathrm{c}$ presents a stable periodicity and rapid response during the stretch-release tests under a regular intermittent stress of $1.33 \mathrm{MPa}$ for applied strain of $20 \%$. Each periodic stretch-release for $20 \%$ of strain was completed in $6 \mathrm{~s}$ corresponding to nearly 1.03 of $\Delta \mathrm{R} / \mathrm{R}_{0}$. Moreover, the sensing stability was measured for the strain sensor under a stress of $2.0 \mathrm{MPa}$ like the periodicity test. The change of $\Delta R / R_{0}$ values under $20 \%$ of the applied strain was repeated for 1000 cycles, as shown by the measured broken lines in Figure 6d, indicating a good signal repeatability using the as-fabricated composite film.

As shown in Figure $6 \mathrm{~b}$, a stretching curve with the relationship of resistance and strain gives two different applied strains $(20 \%, 40 \%)$ for the change of $\Delta R / R_{0}$. Figure 6e gives the signal periodicity (in 6 and $12 \mathrm{~s}$ ) of cyclic applied strain, indicating the strain sensor had a high responsiveness of resistance $\left(1.05=\Delta R / R_{0}\right)$ in small applied strains. The developed strain sensor manifests high reliability and reversible resistance change. Then, under different applied stresses of $0.67,1.33,2.0,2.67$, and $3.33 \mathrm{MPa}$ for the variation of $\Delta R / R_{0}$, the strain sensor presents the corresponding strains from $10 \%$ to $60 \%$, as shown in Figure $6 \mathrm{f}$, related to the variation of $\Delta \mathrm{R} / \mathrm{R}_{0}$ from 1.025 to 1.065 . Here, it is noted that a footstep incremental curve appears on the repeatability test with the increase of applied stress, which is ascribed to the limited recovery time to the applied strain, giving rise to a gradual increase of the initial value of $\Delta \mathrm{R} / \mathrm{R}_{0}[49]$.

\subsection{Comparison of Sensing Performance Before, During, and After SME}

Figure 7 shows the change of the measured electrical resistance of the sample with the increase of strain up to $40 \%$, in which three kinds of sample dry states are illustrated based on a water-induced SME program, including original, temporarily fixed, and recovered shapes of nanocomposite samples.
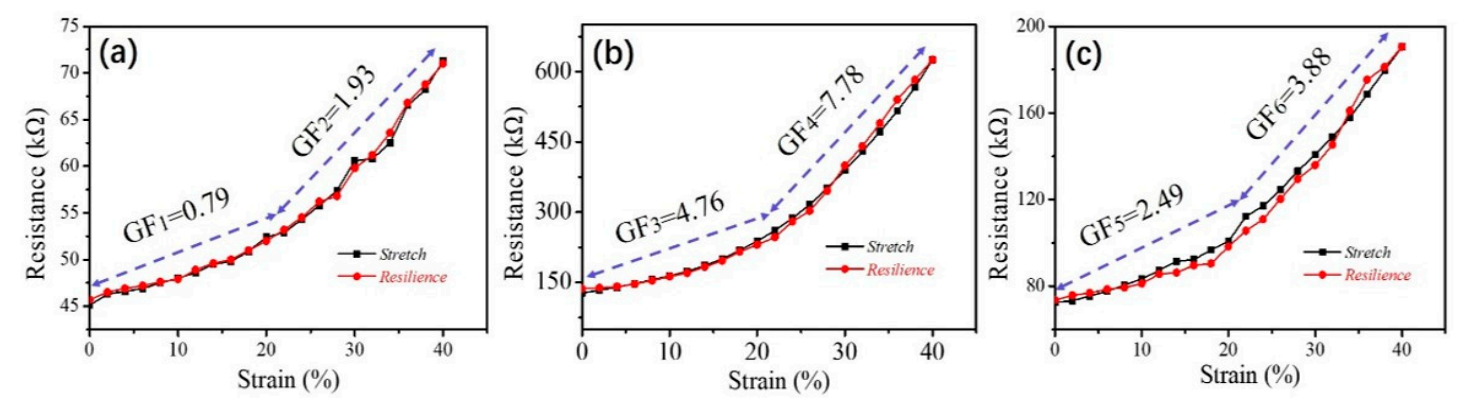

Figure 7. Cyclic test of relative resistance change as strain increases up to $40 \%$, (a) origin sample; (b) temporarily stretched sample (strain of 40\%); (c) recovered sample from the fixed strain of $40 \%$.

In Figure 7a, the length, width, and thickness of the measured sample are 50, 10, and $0.15 \mathrm{~mm}$, respectively. The tested resistance-strain curve show two phases of GF values of 0.79 and 1.93, indicating the sensitivity of the sample sensor increases with the increase of the tensile strain, and the non-linear growth of the slope also conforms to the tensile properties of polymer materials. Figure $7 \mathrm{~b}$ shows the highly increased resistance of the sample with a continued increase of the stretch strain beginning from its temporarily fixed strain. The stretch curve shows two phases roughly $(0 \%-20 \%$ and $20 \%-40 \%$ ) with GF mean values of 4.76 and 7.78 , respectively, which are larger than the values from Figure 7a. This indicates the sample has a higher sensitivity (higher GF values) in a temporarily stretched shape, because the average distance of two neighboring CNTs in microscale is enlarged during stretch. This leads to a smaller number of contacts of CNTs in the fabricated nanocomposite 
and an increased resistance [47]. The data in Figure 7c is derived from the sensitivity of the recovered dry sample induced by water. Here, the measured GF values are 2.49 and 3.88 for two phases of tensile strains.

In comparison with Figure 7a,c, it must be pointed out that the original and recovered samples present different sensing sensitivities. An indication is explored for a reason that the distribution of CNTs in the recovered sample has an irreversible destruction even after a shape recovery process. Nonetheless, the recovery process still reduces GF values from shape fixed states, indicating a repair function to the sensor, especially when it experiences long-time usage with relaxation. Thus, the sensor with SME may satisfy many application scenarios around water/wet stimulation by exploring the sensor's sensing performance in three situations: In-situ, stretched and fixed or restored, and recovered states [47].

\subsection{Application Demonstration of Limb Motion}

The as-made TPU/CNF-C/CNTs film strain sensors can be used for wearable electronics, because the stretchable film can easily adhere to the surface of cotton-blended spandex fabric. For human motions, different parts of the human body in diverse small scales can be detected using the strain sensors, such as movements of the finger and arm [50]. Here, the strain sensor was adhered to the joint of the index finger and the joint of the arm with cotton-blended spandex fabric using double-sided tape (inset of Figure 8a). The attached sensor recorded each bending cycle (bending finger and arm angle of $90^{\circ}$ ), with the sensor stretching and releasing once (inset of Figure $8 \mathrm{a}, \mathrm{b}$ ). The measured broken lines with variable $\Delta R / R_{0}$ values are related to the stretching/releasing of the length of the strain sensor via the human joints bending. The periodic sensing signals cyclically increase and decrease under variable strains as a response to the motion of different parts of the human body [51,52]. The test results showed that the strain sensor satisfies the detection requirements of finger and arm motions, and the results have reasonable accuracy to reflect each human motion.
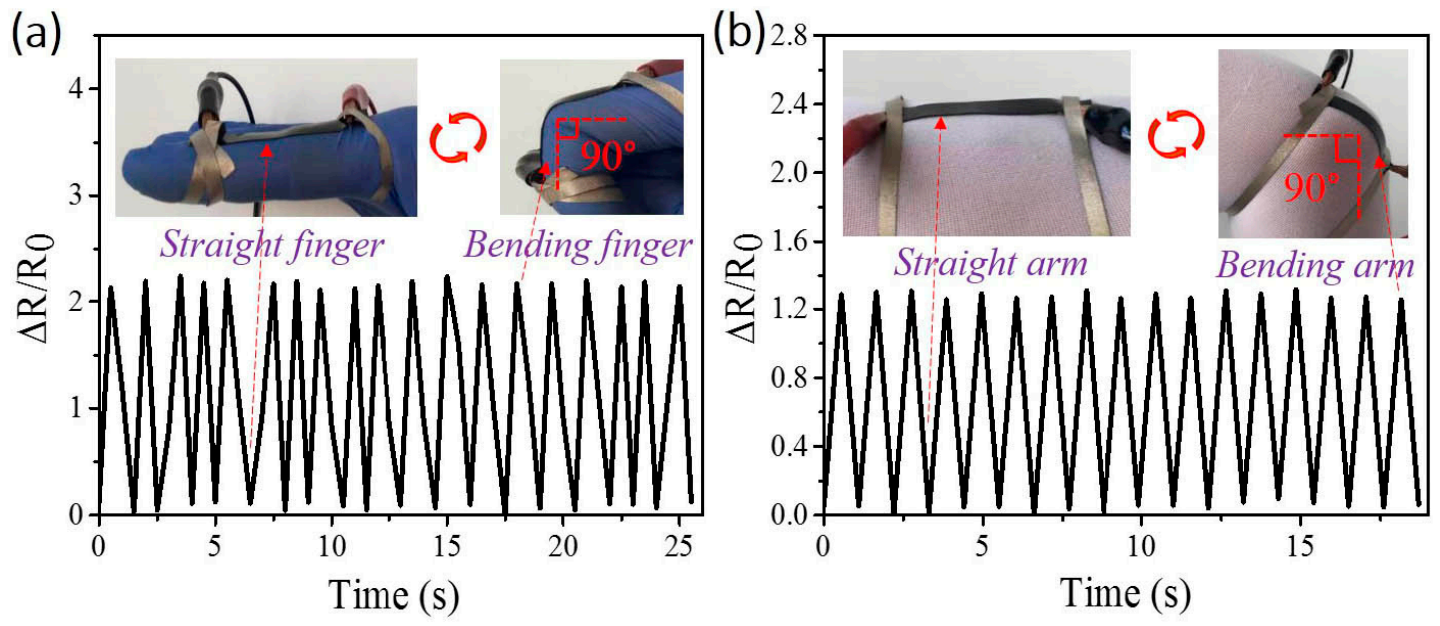

Figure 8. Human motion monitoring using the as-fabricated sensor, (a) relative resistance variations $\left(\Delta \mathrm{R} / \mathrm{R}_{0}\right)$ versus time for blending and release of the index finger, inset: snapshots of one bending cycle. (b) $\Delta \mathrm{R} / \mathrm{R}_{0}$ for TPU/CNF-C/CNTs strain sensors according to bending motions, inset: one bending cycle of arm, the bending motion degree of the arm at angle of $90^{\circ}$.

\section{Conclusions}

A TPU/CNF-C/CNTs hybrid nanocomposite was successful prepared with water-sensitive SME, in which the crystalline phase was characterized as net points and hydrogen bonds as the switch unit. The mechanism indicated that CNF-C brought a large amount of hydrogen bonds (FT-IR spectra) and crystals (XRD spectra) into the TPU matrix and CNTs brought electrical conductivity (multimeter test) and sensing performance into the TPU system. Experimental measurements showed that $6 \mathrm{wt} \%$ content 
of CNTs in the TPU/CNF-C/CNTs sample displayed the best mechanical properties, such as the highest breaking strength and elongation. The detailed stress at break was measured up to $31.78 \mathrm{MPa}$, and the corresponding elongation was $904.09 \%$. The combination of mechanical and conductive adaptability of a percolation network of CNF-C and CNTs, and the entropic elasticity of TPU are the basis to achieve shape fixity for temporary deformation in dry and water states, and recover the original shape after wetting, cool-off, etc. Temporary shape fixation $\left(49.65 \%\right.$ of $\left.R_{f}\right)$ and shape recovery $\left(76.64 \%\right.$ of $\left.R_{r}\right)$ of TPU/CNF-C/CNTs sample stimulated by water demonstrated that the as-fabricated TPU-based composite are a kind of smart and functional material.

A SME program showed that the as-fabricated TPU/CNF-C/CNTs sample displayed a fast response (120 s) of the manually deformed shape to recover its original shape when exposed to water, indicating that the involvement of CNF-C in the TPU macromolecular networks improves the water stimulus SME behavior. Furthermore, the involvement of CNTs into TPU macromolecular networks showed a good conductivity with $0.142 \mathrm{~S} / \mathrm{m}$, such that the elasticity and conductivity endowed the materials with good sensing property. The sensitivity $(\mathrm{GF}=1.93)$, periodicity (10 times per minute), and signal repeatability (effective $>1000$ ) were all measured with good characteristics for applications as a strain sensor. Demonstrations of the sensor used on the bending of the finger and arm were carried out, revealing that such a material sensor can detect human motion effectively. In this work, water-sensitive SME was shown to endow the sensor with more stability when usage repeatability exceeds a point in a wet environment. The combination of SME and sensing property may apply the new material to develop next generations of water-responsive sensors, actuators, or biomedical devices.

Author Contributions: Data curation, R.L.; Formal analysis, G.W.; Funding acquisition, H.K.; Investigation, Y.G.; Methodology, Y.G.; Resources, X.H.; Supervision, X.X.; Writing—original draft, G.W.; Writing一review \& editing, X.X.

Acknowledgments: This work was financially supported by National Natural Science Foundation of China (Grant No. 51703083), Natural Science Foundation of Jiangsu Province (Grant No. BK20160157), Postgraduate Research \& Practice Innovation Program of Jiangnan University (JNKY19_031) and the Open Project Program of Fujian Key Laboratory of Novel Functional Textile Fibers and Materials (Minjiang University), China (No. FKLTFM1706).

Conflicts of Interest: The authors declare no conflict of interest.

\section{References}

1. Luo, H.; Li, Z.; Yi, G. Multi-stimuli responsive carbon nanotube-shape memory polymeric composites. Mater. Lett. 2014, 137, 385-388. [CrossRef]

2. Liu, T.; Zhou, T.; Yao, Y. Stimulus methods of multi-functional shape memory polymer nanocomposites: A review. Composites Part A. Appl. Sci. Manuf. 2017, 100, 20-30. [CrossRef]

3. Bai, Y.; Chen, X. A fast water-induced shape memory polymer based on hydroxyethyl cellulose/graphene oxide composites. Composites Part A. Appl. Sci. Manuf. 2017, 103, 9-16. [CrossRef]

4. Xiao, X.; Gu, Y.; Wu, G. Controllable crimpness of animal hairs via water-stimulated shape fixation for regulation of thermal insulation. Polymers 2019, 11, 172. [CrossRef] [PubMed]

5. Xiao, X.; Zhou, H.; Qian, K. Mechanism study of biopolymer hair as a coupled thermo-water responsive smart material. Smart Mater. Struct. 2017, 26, 035023. [CrossRef]

6. Wu, T.; O'Kelly, K.; Chen, B. Poly (vinyl alcohol) particle-reinforced elastomer composites with water-active shape-memory effects. Eur. Polym. J. 2014, 53, 230-237. [CrossRef]

7. Nath, T.; Chou, H.P.; Disawal, R. Comparative study of electrically and hot water actuated shape memory alloy using developed thermo-mechanical cycletest bench. Def. Sci. J. 2017, 67, 101-107.

8. Wu, T.; Frydrych, M.; O'Kelly, K. Poly (glycerol sebacate urethane)-cellulose nano- composites with water-active shape-memory effects. Biomacromolecules 2014, 15, 2663-2671. [CrossRef]

9. Qi, X.; Yao, X.; Deng, S. Water-induced shape memory effect of graphene oxide reinforced polyvinyl alcohol nanocomposites. J. Mater. Chem. A 2014, 2, 2240-2249. [CrossRef]

10. Bai, Q.; Zhang, G.; Xu, B. Thermal and water dual-responsive shape memory poly (vinyl alcohol)/ $/ \mathrm{Al}_{2} \mathrm{O}_{3}$ nanocomposite. RSC Adv. 2015, 5, 91213-91217. [CrossRef] 
11. Wang, Y.; Cheng, Z.; Liu, Z. Cellulose nanofibers/polyurethane shape memory composites with fast water-responsivity. J. Mater. Chem. B. 2018, 6, 1668-1677. [CrossRef]

12. Chalissery, D.; Pretsch, T.; Staub, S. Additive manufacturing of information carriers based on shape memory polyester urethane. Polymers 2019, 11, 1005. [CrossRef] [PubMed]

13. Elseddawy, A.M.; Zein, W.A.; Phillips, A.H. Carbon nanotube-based nanoelectromechanical resonator as strain sensor. J. Comput. Theor. Nanosci. 2014, 11, 1174-1177. [CrossRef]

14. Nie, B.; Li, X.; Shao, J. Flexible and transparent strain sensors with embedded multiwalled-carbon-nanotubes meshes. ACS Appl. Mater. Interfaces 2017, 9, 40681-40689. [CrossRef] [PubMed]

15. Huang, M.; Dong, X.; Gao, Y. Probing the structure evolution/orientation induced by interaction between polyurethane segments and $\mathrm{SiO} 2$ surface in shape memory process. Polymer 2014, 55, 4289. [CrossRef]

16. Montero de Espinosa, L.; Meesorn, W.; Moatsou, D. Bioinspired polymer systems with stimuli-responsive mechanical properties. Chem. Rev. 2017, 117, 12851-12892. [CrossRef] [PubMed]

17. Tan, L.; Hu, J.; Ying, R.K. Quick water-responsive shape memory hybrids with cellulose nanofibers. J. Polym. Sci. Part A Polym. Chem. 2017, 55, 767-775. [CrossRef]

18. Bumbudsanpharoke, N.; Lee, W.; Chung, U. Study of humidity-responsive behavior in chiral nematic cellulose nanocrystal films for colorimetric response. Cellulose 2018, 25, 305-317. [CrossRef]

19. Zhu, Y.; Hu, J.; Luo, H. Rapidly switchable water-sensitive shape-memory cellulose/elastomer nano-composites. Soft Matter 2012, 8, 2509-2517. [CrossRef]

20. Li, Y.; Chen, H.; Liu, D. pH-responsive shape memory poly (ethylene glycol)-poly ( $\varepsilon$-caprolactone)-based polyurethane/cellulose nanocrystals nanocomposite. ACS Appl. Mater. Interfaces 2015, 7, 12988-12999. [CrossRef]

21. Liu, Y.; Li, Y.; Yang, G. Multi-stimulus-responsive shape-memory polymer nanocomposite network cross-linked by cellulose nanocrystals. ACS Appl. Mater. Interfaces 2015, 7, 4118-4126. [CrossRef]

22. Ryu, S.; Lee, P.; Chou, J.B. Extremely elastic wearable carbon nanotube fiber strain sensor for monitoring of human motion. ACS Nano 2015, 9, 5929-5936. [CrossRef] [PubMed]

23. Huang, J.R.; Her, S.C.; Yang, X.X. Synthesis and characterization of multi-walled carbon nanotube/graphene nanoplatelet hybrid film for flexible strain sensors. Nanomaterials 2018, 8, 786. [CrossRef] [PubMed]

24. Yu, K.; Liu, Y.; Liu, Y.; Peng, H.X.; Leng, J. Mechanical and shape recovery properties of shape memory polymer composite embedded with cup-stacked carbon nanotubes. J. Intell. Mater. Syst. Struct. 2013, 25, 1264-1275. [CrossRef]

25. Du, F.P.; Ye, E.Z.; Yang, W.; Shen, T.H.; Tang, C.Y.; Xie, X.L.; Law, W.C. Electroactive shape memory polymer based on optimized multi-walled carbon nanotubes/polyvinylalcohol nanocomposites. Compos. Part B Eng. 2015, 68, 170-175. [CrossRef]

26. Chen, L.; Li, W.; Liu, X. Carbon nanotubes array reinforced shape-memory epoxy with fast responses to low-power microwaves. J. Appl. Polym. Sci. 2019, 136, 47563. [CrossRef]

27. Wang, C.; Wang, H.; Zou, F. Development of polyhydroxyalkanoate-based polyurethane with water-thermal response shape-memory behavior as new 3D elastomers scaffolds. Polymers 2019, 11, 1030. [CrossRef] [PubMed]

28. Li, S.; Gu, Y.; Wu, G. A flexible piezoresistive sensor with highly elastic weave pattern for motion detection. Smart Mater. Struct. 2019, 28, 035020. [CrossRef]

29. Frewin, C.L.; Ecker, M.; Joshi-Imre, A. Electrical properties of thiol-ene-based shape memory polymers intended for flexible electronics. Polymers 2019, 11, 902. [CrossRef] [PubMed]

30. Xiao, X.L.; Wu, G.Z.; Zhou, H.T. Preparation and property evaluation of conductive hydrogel using poly (vinyl alcohol)/polyethylene glycol/graphene oxide for human electrocardiogram acquisition. Polymers 2017, 9, 259. [CrossRef] [PubMed]

31. Zhou, J.; Xu, X.; Xin, Y. Coaxial thermoplastic elastomer-wrapped carbon nanotube fibers for deformable and wearable strain sensors. Adv. Funct. Mater. 2018, 28, 1705591. [CrossRef]

32. Karimov, K.S.; Khalid, F.A.; Chani, M.T.S. Carbon nanotubes based strain sensors. Measurement 2012, 45, 918-921. [CrossRef]

33. Wang, H.; Luo, H.; Zhou, X. Conductive multi-shape polymer composites towards stimuli sensing. Mater. Lett. 2017, 198, 132-135. [CrossRef] 
34. Jiang, G.; Zhang, M.; Feng, J. High oxygen barrier property of poly (propylene carbonate)/polyethylene glycol nanocomposites with low loading of cellulose nanocrytals. ACS Sustain. Chem. Eng. 2017, 5, 11246-11254. [CrossRef]

35. Gong, J.; Hosaka, E.; Sakai, K. Processing and thermal response of temperature-sensitive-gel (TSG)/polymer composites. Polymers 2018, 10, 486. [CrossRef] [PubMed]

36. Mao, Y.; Miyazaki, T.; Sakai, K. A 3D printable thermal energy storage crystalline gel using mask-projection stereolithography. Polymers 2018, 10, 1117. [CrossRef] [PubMed]

37. Chen, F.; Chen, Q.; Song, Q. Strong and stretchable polypyrrole hydrogels with biphase microstructure as electrodes for substrate-free stretchable supercapacitors. Adv. Mater. Interfaces 2019, 6, 1900133. [CrossRef]

38. Wu, G.Z.; Li, S.M.; He, W.T. Effect of percentage of graphene oxide on phase transition of water induced shape memory behavior of PVA-go-PEG hydrogel. Mater. Res. Express 2018, 5, 115703. [CrossRef]

39. Zhang, Z.; Qi, X.; Li, S. Water-actuated shape-memory and mechanically-adaptive poly (ethylene vinyl acetate) achieved by adding hydrophilic poly (vinyl alcohol). Eur. Polym. J. 2018, 98, 237-245. [CrossRef]

40. Yan, J.; Rodrigues, M.T.F.; Song, Z. Reversible formation of g-C3N4 3D hydrogels through ionic liquid activation: Gelation behavior and room-temperature gas-sensing properties. Adv. Funct. Mater. 2017, 27, 1700653. [CrossRef]

41. Bai, Y.; Jiang, C.; Wang, Q. Multi-shape-memory property study of novel poly ( $\varepsilon$-caprolactone)/ethyl cellulose polymer networks. Macromol. Chem. Phys. 2013, 214, 2465-2472. [CrossRef]

42. Wang, W.; Liu, D.; Lu, L. The improvement of the shape memory function of poly ( $\varepsilon$-caprolactone)/ nano-crystalline cellulose nanocomposites via recrystallization under a high-pressure environment. J. Mater. Chem. A 2016, 4, 5984-5992. [CrossRef]

43. Nicharat, A.; Shirole, A.; Foster, E.J. Thermally activated shape memory behavior of melt-mixed polyurethane/cellulose nanocrystal composites. J. Appl. Polym. Sci. 2017, 134, 45033. [CrossRef]

44. Du, Y.; Li, D.; Liu, L. Recent achievements of self-healing graphene/polymer composites. Polymers 2018, 10, 114. [CrossRef] [PubMed]

45. Xiao, X.; Hu, J.; Gui, X. Is biopolymer hair a multi-responsive smart material? Polym. Chem. 2017, 8, $283-294$. [CrossRef]

46. Yang, G.; Wan, X.; Liu, Y. Luminescent poly (vinyl alcohol)/carbon quantum dots composites with tunable water-induced shape memory behavior in different $\mathrm{pH}$ and temperature environments. ACS Appl. Mater. Interfaces 2016, 8, 34744-34754. [CrossRef] [PubMed]

47. Huang, J.Y.; Li, D.W.; Zhao, M. Highly stretchable and bio-based sensors for sensitive strain detection of angular displacements. Cellulose 2019, 26, 3401-3413. [CrossRef]

48. Trung, T.Q.; Lee, N.E. Flexible and stretchable physical sensor integrated platforms for wearable human-activity monitoringand personal healthcare. Adv. Mater. 2016, 28, 4338-4372. [CrossRef]

49. Liang, B.; Lin, Z.; Chen, W. Ultra-stretchable and highly sensitive strain sensor based on gradient structure carbon nanotubes. Nanoscale 2018, 10, 13599-13606. [CrossRef]

50. Park, J.J.; Hyun, W.J.; Mun, S.C.; Park, Y.T.; Park, O.O. Highly stretchable and wearable graphene strain sensors with controllable sensitivity for human motion monitoring. ACS Appl. Mater. Interfaces 2015, 7, 6317-6324. [CrossRef]

51. Wang, X.; Sparkman, J.; Gou, J. Strain sensing of printed carbon nanotube sensors on polyurethane substrate with spray deposition modeling. Compos. Commun. 2017, 3, 1-6. [CrossRef]

52. Ma, L.; Wei, Y.; Wang, Y. Multi-dimensional strain sensor based on carbon nanotube film with aligned conductive networks. Compos. Sci. Technol. 2018, 165, 190-197. [CrossRef]

(C) 2019 by the authors. Licensee MDPI, Basel, Switzerland. This article is an open access article distributed under the terms and conditions of the Creative Commons Attribution (CC BY) license (http://creativecommons.org/licenses/by/4.0/). 